\title{
O Goethe de Lukács
}

Filipe de Freitas Gonçalves ${ }^{i}$

\section{RESENHA}

LUKÁCS, György. Goethe e seu tempo. São Paulo: Boitempo, 2021. 221 p.

O novo volume da Biblioteca Lukács da Boitempo oferece-nos um conjunto de ensaios em que o marxista húngaro discute um dos autores que são peça chave para compreender sua obra crítica. Com muita justiça, Miguel Vedda (2021, p. 9), na apresentação que introduz a obra, diz que, parafraseando o título do ensaio "Meu caminho para Marx”, “em Lukács, há um caminho para Goethe que não é menos importante e frutífero que aquele vinculado a Marx no ensaio de 1933”. Ao longo de seu texto, Vedda apresenta-nos esse caminho, por vezes tortuoso, que percorre Lukács ao longo de sua vida em direção a uma compreensão aprofundada do trabalho artístico de Goethe.

O volume publicado pela Boitempo é, de alguma forma, o resultado de um longo caminho percorrido pelo autor, e também das respostas imediatas que ele dava aos problemas de seu tempo. Composto por cinco ensaios escritos entre 1934 e 1936 e um prefácio de 1947, Goethe e seu tempo articula não apenas uma visão sobre a obra de Goethe, como o título indica, mas também o posicionamento preciso que sua criação artística e teórico assume diante das questões de seu tempo, sejam elas entendidas como questões estritamente estéticas, sejam elas vistas em sua relação com os problemas políticos.

O que esse conjunto de textos expõe, antes de tudo, é uma tentativa de intervir no campo da história da literatura, articulando o conjunto fundamental de problemas que o período de Goethe apresenta-lhe e as respostas que ele e seus interlocutores (Schiller e Hölderlin principalmente) esboçam para esses problemas. Enquadrar o trabalho de Lukács como história da literatura, para aqueles que o conhecem mais de perto, pode parecer uma heterodoxia, já que ele demonstra, ao longo de sua obra certa resistência com

\footnotetext{
${ }^{\mathrm{i}}$ Mestre em Estudos Literários pela Universidade Federal de Minas Gerais (UFMG). ORCID: http://orcid.org/0000-0003-2808-0746 | lipe.ton.fr@gmail.com
} 
esse campo. Veja-se, por exemplo, o que ele diz em sua autobiografia sobre sua tentativa de ser historiador da literatura:

\begin{abstract}
Eu queria me tornar historiador da literatura alemã. Fui para o exterior acreditando ingenuamente que os historiadores da literatura realmente movessem as coisas. Gostaria de contar um episódio a esse respeito, pois foi, por assim dizer, de importância decisiva para a minha vida. Discutia-se, naquele momento, a cor dos olhos da Lotte no Werther, a Lotte tinha olhos azuis, mas, na realidade, seus olhos eram pretos. Alguém havia escrito um longo ensaio sobre o assunto. Vi nisso a encarnação daquilo que Hatvany chama de ciência do que não merece ser sabido (LUKÁCS, 2017, p. 54).
\end{abstract}

A historiografia com a qual ele debate nos ensaios sobre Goethe pratica exatamente uma manipulação dos detalhes e, na sua incapacidade de articulação diante dos problemas globais do tempo, integra Goethe e seus contemporâneos nas fileiras do fascismo, contra o qual a produção lukacsiana da década de 1930 se levanta. Trata-se, portanto, de uma recuperação daquilo que ele chama de "humanismo burguês revolucionário", que poderia e deveria ser reivindicado pelos comunistas como parte do legado revolucionário da burguesia, decadente e reacionária depois de 1848.

Nesse sentido, o problema fundamental em torno do qual todas as obras apresentadas posicionam-se é a Revolução Francesa. Assim, o erro de avaliação da obra de Hölderlin, tomada pelos fascistas como prenúncio de sua estética mistificadora, seria exatamente a incompreensão de sua relação com o jacobinismo de 1794: se Hegel e Goethe teriam se adaptado ao mundo burguês estabelecido após a revolução, Hölderlin constituiria uma obra que se debate diante do fracasso do humanismo da revolução burguesa. É também assim que se pode, segundo Lukács, avaliar o verdadeiro sentido do Classicismo de Weimar e, de modo geral, a voga da Antiguidade nas reflexões desse período: em sua relação com o uso feito pelos revolucionários e colocado em evidência por Marx, da Antiguidade, a revolução como uma tentativa de reviver a pólis, e o mundo antigo como símbolo de simbiose entre homem e natureza, ou seja, como superação da dicotomia fundamental entre bourgeois e citoyen que o desenvolvimento do capitalismo cada vez mais evidenciava. As esperanças desses revolucionários alemães era exatamente que a revolução burguesa levada a cabo daria fim, nos limites do mundo burguês, às contradições do capitalismo nascente e já notadas por eles. Diante desse ideal e de seu fracasso é que se constrói o tempo de Goethe que Lukács está descrevendo. 
O caráter específico de alemães desses revolucionários não pode também deixar de ser notado, já que é um dos aspectos mais importantes da apreciação lukacsiana. Esse caráter, ele o explora de forma geral no prefácio de 1947 e aparece ao longo dos ensaios como determinação essencial. Em relação aos países centrais, a Alemanha seria caracterizada por um desenvolvimento em que a burguesia, diferentemente da França e da Inglaterra, não teria suplantado pela via revolucionária o mundo feudal contra o qual se levantava, mas teria optado pela via da conciliação com o atraso feudal, marca fundamental de sua desintegração e de seu subdesenvolvimento em relação aos países centrais. Isso que apresentamos de forma resumida é visto no prefácio como uma forma de interpretar a história alemã desde as derrotas das revoluções camponesas à ascensão do nacional-socialismo em 1933, ou seja, trata-se de uma hipótese de interpretação de um amplo arco histórico e matizada em vários de seus momentos. Essa especificação revelanos um dos aspectos mais instigantes da história da literatura de Lukács: atuando no interior de um esquema do desenvolvimento global de um longo arco histórico, ele é capaz de determinar e matizar posições específicas.

Vejamos como isso se dá nos ensaios sobre Werther e Wilhem Meister. Logo no começo de seu primeiro ensaio, temos uma visão profundamente heterodoxa sobre o posicionamento histórico da obra: “(...) a repercussão extraordinariamente ampla e profunda de Werther em todo o mundo tornou evidente o papel de liderança do Iluminismo alemão" (LUKÁCS, 2021, p. 43). A novidade dessa perspectiva está no fato de que Lukács vê o Werther não como obra romântica, mas iluminista. Depois de criticar a oposição entre intelecto e sentimento como a que sustentaria a diferenciação entre Iluminismo e Romantismo, Lukács oferece um posicionamento preciso do Werther em relação aos problemas de seu tempo:

\footnotetext{
O ponto central de Werther é constituído pelo grande problema do humanismo revolucionário burguês, o problema do desenvolvimento livre e universal da personalidade humana. (...) O caráter profundo e multifacetado da formulação do problema pelo jovem Goethe se deve a que ele discernia a oposição entre personalidade e sociedade burguesa não só em relação ao absolutismo semifeudal de pequeno formato da Alemanha de seu tempo, mas também em relação à sociedade burguesa em geral. (...) (LUKÁCS, 2021, p. 48-49).
} 
E, depois, detalha ainda mais o posicionamento da obra no interior do desenvolvimento do Iluminismo, entendido como preparação ideológica da Revolução Francesa:

\begin{abstract}
No jovem Goethe, essa luta trágica pela realização dos ideais humanistas está intimamente vinculada com o caráter popular de suas aspirações. Exatamente nesse sentido, o jovem Goethe dá continuidade às tendências rousseaunianas em oposição ao aristocratismo distinto de Voltaire, cujo legado se tornaria importante para o Goethe posterior, bastante decepcionado e resignado. (...) politicamente o jovem Goethe não era nenhum plebeu revolucionário, nem mesmo dentro do que era possível na Alemanha, nem sequer no sentido do jovem Schiller. No caso dele, portanto, a faceta plebéia não aparece na forma política, mas como oposição entre os ideais revolucionários humanistas e a sociedade estamental do absolutismo feudal e o filisteísmo. Todo o Werther é uma confissão ardente por aquele novo homem que surge no decorrer da preparação para a revolução burguesa, por aquela humanização, por aquele despertar da atividade universal do homem produzido pelo desenvolvimento da sociedade burguesa - e, ao mesmo tempo, condenado tragicamente à ruína (LUKÁCS, 2021, p. 52-53).
\end{abstract}

E conclui Lukács: "Essa beleza não é o resultado da genialidade do jovem Goethe.

Ela advém do fato de que Werther é o produto do período heróico pré-revolucionário do desenvolvimento burguês (...)" (LUKÁCS, 2021, p. 59). Se nos voltarmos para sua caracterização do Wilhelm Meister, encontraremos outro tipo de localização históricoliterária:

O Wilhelm Meister de Goethe é o mais importante produto da transição da literatura romanesca do século XVIII para o século XIX. Ele porta os traços dos dois períodos de desenvolvimento do romance moderno, tanto em termos ideológicos quanto em termos artísticos (LUKÁCS, 2021, p. 61).

E, depois de um longo parágrafo retomando o desenvolvimento dos ideais humanistas desde o Renascimento, ele coloca em evidência a posição específica do Meister: 
Em seguida, específica mais ainda a posição histórica do texto que está comentando:

\begin{abstract}
Assim, Wilhelm Meister se situa ideologicamente na fronteira entre duas épocas: figura a crise trágica dos ideais burgueses de humanidade até o início de sua extrapolação - por ora utópica - do quadro da sociedade burguesa. $\mathrm{O}$ fato de Goethe ter pintado esse caráter de crise com as cores vívidas da perfeição artística, do contentamento ideológico esperançoso, foi, como vimos, reflexo da vivência da Revolução Francesa. Porém, essa explosão de cores não é capaz de encobrir o abismo trágico que se abre aqui para os melhores representantes da burguesia revolucionária. Tanto ideológica quanto artisticamente, Wilhelm Meister é produto de uma crise de transição, de um tempo muito breve de transição. (...) O grande Realismo da primeira metade do século XIX surge já após a conclusão do "período heroico" (...) (LUKÁCS, 2021, p. 78).
\end{abstract}

Essas citações mais longas dos dois primeiros ensaios do livro são importantes porque revelam as qualidades do Lukács historiador da literatura que tantas vezes esconde-se por detrás do crítico, do teórico ou mesmo do filósofo da estética. Seu posicionamento contrário ao sociologismo vulgar, sua defesa da abordagem estética em relação às obras de arte e sua discordância fundamental em relação às conclusões da historiografia de seu tempo - caracterizada por ele de burguesa e decadente em mais de uma circunstância no livro recém-publicado - acabam afastando seus textos de uma abordagem mais propriamente historiográfica, o que não significa, como estamos tentando mostrar, que, a contrapelo, ele constrói uma história literária complexa e matizada.

Veja-se primeiro como redesenha nas primeiras páginas de seu ensaio sobre o Werther a forma como se vê a transição entre o século XVIII e o XIX. Chama atenção o fato de que ele organiza tudo em torno de um conflito ideológico fundamental e não em torno de disputas literárias específicas: essas disputas, que aparecem ao longo de todo o livro na forma de matizes do enquadramento geral, respondem ao posicionamento dos autores em relação ao conflito histórico-social fundamental de seu tempo. Assim, a linha demarcatória entre a literatura do Iluminismo e aquela do Romantismo é completamente redefinida e se tem um conceito de Romantismo bem mais delimitado do que as abordagens historiográficas (cf. GUSDORF, 2011) costumam ser capazes de oferecer.

Ainda dentro desse enquadramento, temos uma demarcação bem definida da posição de cada obra: observe-se como o Werther e o Wilhelm Meister, embora sejam 
obras do mesmo autor e estejam posicionando-se diante das mesmas questões, assumem posturas diferentes porque, no primeiro caso, estaríamos diante de uma obra de preparação à revolução burguesa e, no segundo caso, uma obra que poderia ser considerada a primeira grande reação à Revolução Francesa. A sutileza da colocação histórica de cada uma chama atenção do leitor ainda quando o autor é capaz de desmontar qualquer tentativa de esquematismo: a posição das obras é caracterizada com profunda complexidade. Assim, o Werther é tanto uma obra contra o mundo feudal dos pequenos principados alemães e, por extensão, de todo o feudalismo, como uma obra contra as limitações impostas pela sociabilidade burguesa ascendente. Assim também o Meister guarda, ao mesmo tempo, a afirmação utópica dos ideais do humanismo burguês e a percepção de sua impossibilidade no cotidiano instaurado pelo mundo burguês em ascensão. Não se trata, portanto, de caracterizar as obras como partícipes da luta ideológica da burguesia ascendente contra o atraso feudal, o que seria uma caracterização unidimensional, mas perceber as determinações sociais complexas que agem em sua elaboração. Nesse sentido, a especificidade alemã entra mais uma vez em ação: a posição que Goethe assume e a forma como sua criação literária realiza-se em termos de forma está determinada pelo posicionamento necessariamente conservador de uma burguesia que não acumula força histórica suficiente para se ver livre das imposições das limitações do mundo feudal.

Normalmente, as ideias de Lukács sobre a literatura são ou descartadas como ultrapassadas, marxismo vulgar, quando não consideradas conservadoras por sua crítica às vanguardas, ou então admitidas como um conjunto de verdades por seguidores que, exatamente por isso, constituem uma espécie de gueto no ambiente intelectual brasileiro. É rara uma postura como a de Antonio Candido e Roberto Schwarz, que são profundamente influenciados por Lukács, mas o assimilam criticamente como parte de sua atividade. Esse Goethe e seu tempo publicado pela Boitempo, com suas traduções já conhecidamente prestigiosas, é uma oportunidade de conhecermos um Lukács que simplesmente não pode ser ignorado como anacrônico, como marxista vulgar ou como conservador, um teórico que intervém no campo da história literária revelando-nos caminhos possíveis para a resolução de problemas espinhosos, como a relação entre Iluminismo e Romantismo, como a interpretação dos Estudos Clássicos na virada do século XVIII para o XIX ou ainda o lugar que deve ocupar uma obra tão heterodoxa 
quanto a de Hölderlin. Não apenas por nos oferecer soluções originais ele precisa ser meditado com mais profundidade, mas também porque nos apresenta um método próprio para pensar os problemas de história da literatura - a relação entre o posicionamento sobre os problemas ideológicos fundamentais e a configuração artística de cada obra específica. Se as circunstâncias permitirem que a lista de próximos volumes apresentados depois da última página numerada do livro seja seguida, teremos ainda nos próximos anos muito o que discutir sobre a história da literatura do Lukács amadurecido.

\section{Referências}

GUSDORF, Georges. Le Romantisme. Paris: Payot, 2011. 900 p.

LUKÁCS, Georg. Pensamento vivido: autobiografia em diálogo. São Paulo: Instituto Lukács, 2017. 239 p.

LUKÁCS, György. Goethe e seu tempo. São Paulo: Boitempo, 2021. 221 p.

VEDDA, Miguel. Apresentação. In: LUKÁCS, György. Goethe e seu tempo. São Paulo: Boitempo, 2021. p. 9-29. 